\title{
Fatigue life investigation on a MAC engine piston
}

\author{
Costel Humelnicu*, Valentin Amortila and Elena Mereuta \\ Dunarea de Jos University of Galati, Department of Mechanical Engineering, Domneasca str. 111, \\ Galati, Romania
}

\begin{abstract}
In MAC (Diesel) engines case, the shape of the piston head has an important influence on burning processes and, consequently on engine performance. Since the piston is subjected to high cyclic stresses during the blasting phase, a fatigue phenomenon occur. The piston design and material must provide a high fatigue resistance and a low weight, leading to low dynamic loading of the crank shaft and piston rod. The paper try to investigate the piston fatigue behavior, for several head shapes and materials, in order to establish an optimal design.
\end{abstract}

\section{Introduction}

The piston is one of the most solicited part of the engine, both from mechanical and thermal points of view. Following the engine type (MAC - Diesel or MAS - Otto) and, consequently, the fuel type - there are differences in piston shape, size, mass, materials etc..

In the MAC engines case, the piston head shape has a higher influence on burning processes into the cylinder comparing to the MAS engines [1]. As consequence, there are MAC pistons with different piston heads shapes while MAS piston head is flat

The present paper use CAD (Computer Aided Design) method to investigate the influence of the head shape and material on the fatigue life of the piston with the goal of its optimization. Two shapes (central and offset position of piston head burning chamber) and two materials (aluminium alloy and alloyed steel) will be studied. The goal was to obtain an alloyed steel piston with lowest mass and highest fatigue resistance.

\section{Piston characteristics}

\subsection{Forces}

Apart to the thermal solicitations, which are not the object of this work, the mechanical stresses in the piston are generated by gas pressure and inertia forces [2].

As is presented in Figure 1a, the gas pressure force $\mathrm{F}_{\mathrm{x}}$ acts on the piston head, leading to a bending stress and on piston ring area, leading to a compression stress. The piston rings

\footnotetext{
*Corresponding author: costel.humelnicu@ugal.ro
} 
area is also subjected to an elongation, due to the inertial forces generated by the piston mass.

The second force that acts on the piston is the $F_{\mathrm{s}}$ force (Figure 1b). This one leads to contact stresses between the piston skirt and cylinder. The reduction of these forces can be obtained by a very low space between the piston skirt and cylinder, by offsetting the piston bolt to the cylinder axe or by a combination of both methods.

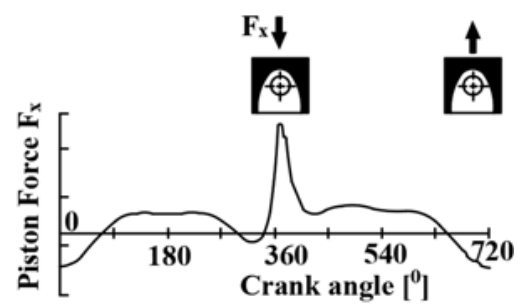

a)

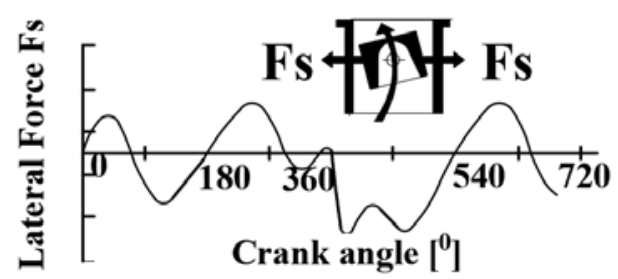

b)

Fig. 1. Forces on the piston: a) gas pressure force $F_{x} ; b$ ) lateral forces $F_{s}[3]$.

\subsection{Materials}

The engines' pistons materials must comply with specific conditions like: high mechanical and thermal resistance, low density, high corrosion resistance and, due to cyclic solicitations, high fatigue resistance.

The classic materials used for MAC pistons are $\mathrm{Al}$ based alloys with $\mathrm{Cu}, \mathrm{Si}, \mathrm{Mg}$ specially designed. Lately, alloyed steels took first place in designers' choice. These materials can be used for powers over $136 \mathrm{CP} /$ litter and pressures over $200 \mathrm{bar}$, due their lower thermal deformation and higher mechanical resistance. This kind of pistons are made by a single piece of material, by forging [4].

\subsection{Shapes}

In Figure 2 are presented two most used MAC aluminium piston shapes. One can observe the piston head burning chamber position (central - Figure $2 \mathrm{a}$ or offset - Figure 2b), with the goal of creating a high turbulence during fuel burning. In order to obtain high compression, some circular spaces must be designed in piston head, allowing valves protection, Figure $2 \mathrm{~b}$.

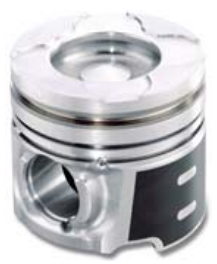

a)

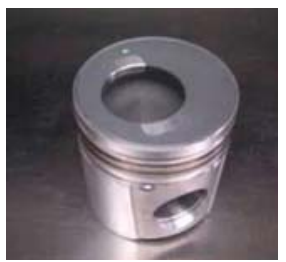

b)

Fig. 2. Aluminium alloy piston shapes: a) Diesel Engine Piston Brand: RK Enterprise [6]; b) Diesel Engine Piston Brand: Cummins [5]. 
In Figure 3, two alloyed steel piston shapes are presented. It can be observed, in Figure $3 \mathrm{~b}$, the optimized shape for lowest mass and higher heat transfer.

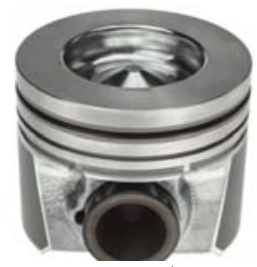

a)

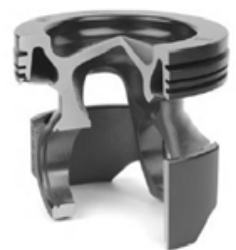

b)

Fig. 3. Alloyed steel piston shapes: a) Diesel Engine Piston Brand: Mahle; b)Diesel Engine Piston Brand: Mahle [6].

\section{Piston analyse}

\subsection{D modeling}

In order to build the $3 \mathrm{~d}$ model for the piston and perform fatigue analysis, SolidWorks package was chosen.

Starting from a 2D sketch, with real piston dimensions, four shapes were built, two for aluminium (Figure 4) and two for steel (Figure 5).

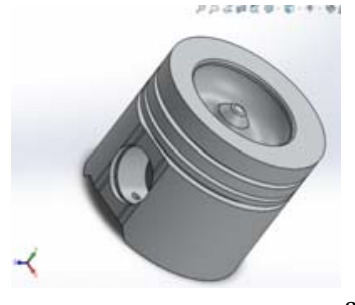

a)

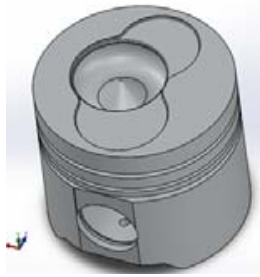

b)

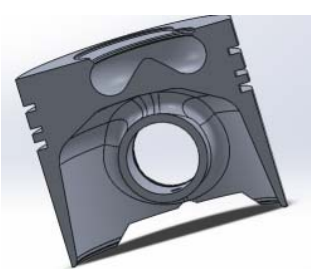

Fig. 4. Aluminium alloy piston: a) central burning chamber; b) offset burning chamber.
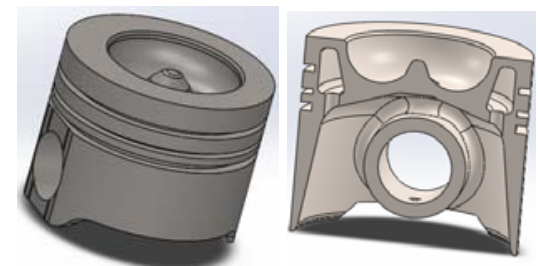

a)
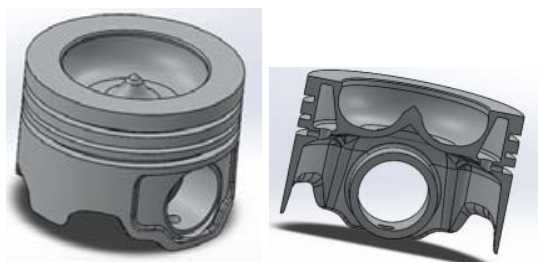

b)

Fig. 5. Alloyed steel piston: a) regular shape; b) low mass optimized shape.

\subsection{Fatigue analyse settings}

Due to cyclic functioning of the engine, the pistons are solicited to fatigue [7]. Taking into account the forces distribution presented before and knowing that the gas pressure force 
leads to the maximum stresses into the piston, can be assumed that the fatigue cycle is a pulsating one $[8,9]$.

As is stated in [10], the conventional base number of cycles for unlimited durability fatigue is $10^{7}$ for steel and $10^{8}$ for aluminium. As consequence, if the piston resist over that number of cycles it can be assumed it will have an unlimited fatigue life.

As simulation parameters' values were chosen $20 \mathrm{MPa}$ for gas pressure (taking into account that in commercial vehicles' engines the gas pressure is around $18 \mathrm{MPa}$ ) and for the number of cycles, the appropriate conventional base number of cycles was used.

For materials, aluminium alloy and alloyed steel fatigue curves were used the SolidWorks materials library since the dedicated materials characteristics are not available for public.

\subsection{Fatigue analyse results}

In order to compare the chosen shapes and materials, the pistons were subjected to fatigue analysis.

\subsubsection{Aluminium pistons}

After fatigue analysis running for aluminium alloy pistons, the results presented in Figure 6 were obtained.

As can be seen in Figure 6a, the minimum fatigue life of the piston with central burning chamber, is $3.848 \times 10^{8}$. In Figure $6 \mathrm{c}$, the results for the piston with offset burning chamber are presented, the total fatigue life being $3.068 \times 10^{8}$. In both cases, the fatigue life is more than the corresponding base number of cycles for this material.

The most sensible area to fatigue damage, yet the damage doesn't occur, is the upper part of the bolt fixture, Figure 6b,d.

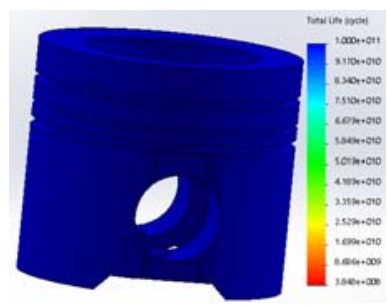

a)

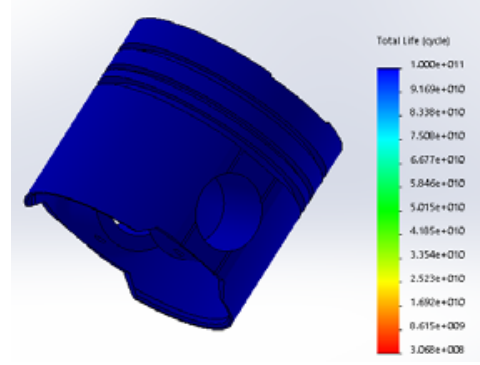

c)

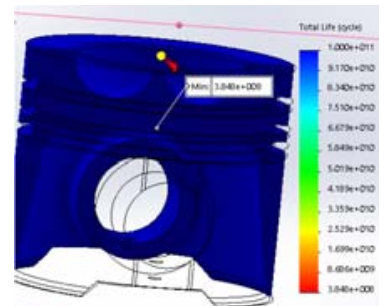

b)

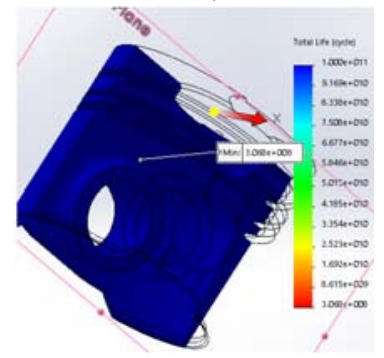

d)

Fig. 6. Aluminium piston, central burning chamber: a) total life [cycles]; b) minimum fatigue life area. 
Taking into account the Figure 6, the conclusion is that the position of the burning chamber doesn't affect the fatigue life of the piston.

\subsubsection{Steel pistons}

Regarding the steel pistons, only the shape with central burning chamber was analysed because in steel case the piston must have an internal circular channel under the head for cooling, visible in Figure 5a,b.

First, the classical shape was investigated and the corresponding results are presented in Figure 7.

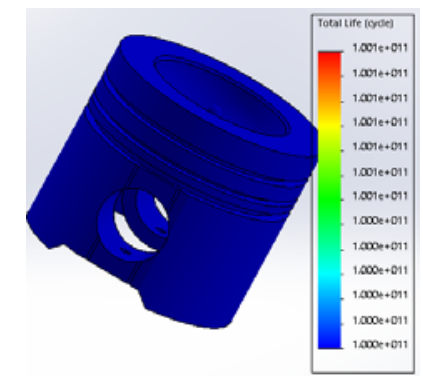

a)

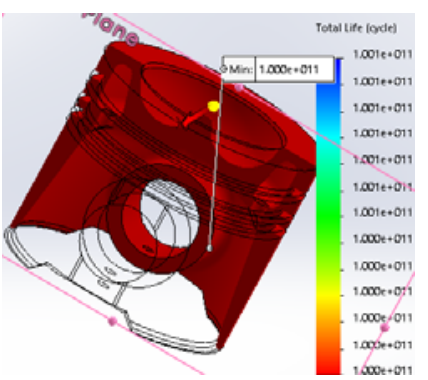

b)

Fig. 7. Steel piston, classical shape: a) total life [cycles]; b) minimum fatigue life area.

As can be observed in Figure $7 \mathrm{a}$, the total fatigue life is far more than the corresponding base number of cycles $\left(10^{7}\right)$, with most sensible area of bolt fixture, Figure $7 \mathrm{~b}$.

Taking into account that the mass of the piston is $\sim 1200$ grams (meanwhile the aluminium one has only $\sim 410$ grams), it is obvious that an optimization is required, in order to decrease the piston mass.

After several procedures, the optimized shape presented in Figure 8 was obtained.

Looking into the Figure $8 \mathrm{a}$, one can see that the total fatigue life is, the same, over the base number of cycles but the piston mass decreased to $\sim 520$ grams. The most sensitive area to fatigue remain the area of bolt fixture, Figure $8 \mathrm{~b}$.

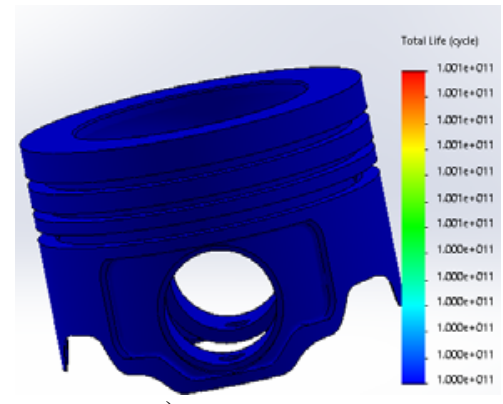

a)

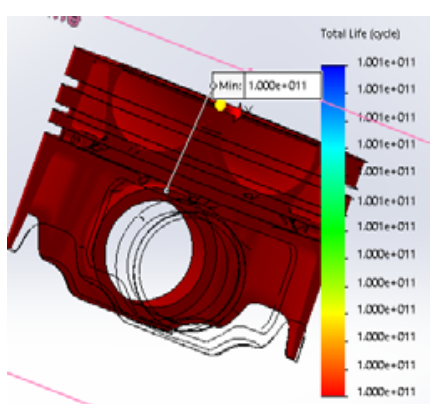

b)

Fig. 8. Steel piston, optimized shape: a) total life [cycles]; b) minimum fatigue life area.

\section{Conclusion}

Taking into account all presented above, a comparison can be made between the studied piston shapes and materials, Table 1. 
Table 1. Aluminium vs steel pistons performances.

\begin{tabular}{|c|c|c|c|c|c|c|}
\hline \multicolumn{4}{|c|}{ Pistons } & \multicolumn{2}{c|}{ Fatigue simulation results } \\
\hline Material & $\begin{array}{c}\text { Central } \\
\text { burning } \\
\text { chamber }\end{array}$ & $\begin{array}{c}\text { Offset } \\
\text { burning } \\
\text { chamber }\end{array}$ & $\begin{array}{c}\text { Classic } \\
\text { shape }\end{array}$ & $\begin{array}{c}\text { Optimized } \\
\text { shape }\end{array}$ & $\begin{array}{c}\text { Total life } \\
\text { [cycles] }\end{array}$ & $\begin{array}{c}\text { Mass } \\
\text { [gr] }\end{array}$ \\
\hline Al-Alloy & $\mathrm{x}$ & - & $\mathrm{x}$ & - & $3.848 \times 10^{8}$ & 415 \\
\hline Al-Alloy & - & $\mathrm{x}$ & $\mathrm{x}$ & - & $3.068 \times 10^{8}$ & 410 \\
\hline Alloyed Steel & $\mathrm{x}$ & - & $\mathrm{x}$ & - & $1 \times 10^{11}$ & 1200 \\
\hline Alloyed Steel & $\mathrm{x}$ & - & - & $\mathrm{x}$ & $1 \times 10^{11}$ & 520 \\
\hline
\end{tabular}

As can be observed into the Table 1, in aluminium alloy case the position of the burning chamber doesn't affect the fatigue life. In both cases the durability overtakes the base number of cycles for the material $\left(10^{8}\right.$ cycles). The offset burning chamber piston's mass value is slightly lower, due to head spaces for the valves.

In alloyed steel case, the fatigue life is far higher than the corresponding base number of cycles for the material $\left(10^{7}\right.$ cycles $)$. The problem is the higher mass value - almost three times comparing with aluminium. This is unacceptable, due to higher inertia forces generated during engine functioning. Applying a shape optimization procedure, a new shape was obtained, with a lower mass value: 520 grams. Taking into account the steel alloyed advantages (lower thermal deformation and higher mechanical resistance) this solution is acceptable.

As final conclusions can be state:

- due to cyclic variations of forces in internal combustion engines, the pistons are subjected, among high thermal and mechanical stresses also to fatigue

- from this point of view, the alloyed steel is more desirable to be used, instead of aluminium alloys

- due to higher density, a shape optimization and fatigue verification is required

- CAD methods allow successfully the optimization of the shape of steel alloyed piston, in order to obtain the lowest mass and higher fatigue life

\section{References}

1. H. Heisler, Advanced Vehicle Technology (Linacre House, OX2, 2002)

2. R. Stone, J.K. Ball, Automotive Engineering Fundamentals (Warrendale PA, 2004)

3. https://knowicengine.wordpress.com/

4. http://www.e-automobile.ro/

5. http://dieselengine-part.sell.everychina.com/

6. http://www.mahle.com/

7. A.A. Stotsky, Automotive Engines, Control, Estimation, Statistical Detection (Springer, 2009)

8. Y. L. Lee, J. Pan, R. Hathaway, M. Barkey, Fatigue Testing and Analysis, theory and Practice (Elsevier, 2005)

9. C. Bathias, A. Pineau, Fatigue of Materials and Structures (Wiley, 2010)

10. I. Dumitru, N. Faur, Computing elements and mechanical resistance applications, (in romanian) (1997) 